\title{
Editorial do dossiê "Cooperação Judiciária Internacional em Matéria Penal" - Problemas actuais em perspectiva global
}

\author{
Editorial of the dossier "International Judicial \\ Cooperation in Criminal Matters" - Current \\ problems in a global perspective
}

Pedro Caeiro ${ }^{1}$

Universidade de Coimbra - Portugal

pcaeiro@fd.uc.pt

https://orcid.org/0000-0002-8899-7399

Resumo: Este editorial descreve, a traços largos, a relevância actual da cooperação judiciária em matéria penal, nomeadamente no que diz respeito à sua relação com o incremento da protecção dos direitos e garantias individuais e à sua reconfiguração em espaços politicamente integrados, com particular ênfase na União Europeia. Seguidamente, procede-se a uma apresentação sumária dos artigos contidos neste volume.

Palavras-Chave: cooperação judiciária em matéria penal; extradição; entrega; mandado de detenção europeu; reconhecimento mútuo; confiança mútua; direitos fundamentais.

ABSTRACT: This editorial provides a bird's eye view of the current relevance of international judicial cooperation in criminal matters, namely in what concerns the issues raised by the growing protection of individual rights, as well as its reconfiguration in politically integrated areas, with a particular emphasis on the

1 Professor auxiliar (com tenure) da Faculdade de Direito da Universidade de Coimbra; investigador integrado do Instituto Jurídico da mesma Universidade; membro do Grupo de Peritos sobre Política Criminal da União Europeia. 
European Union. It then proceeds with a short presentation of the articles contained in this volume.

KEYWORDS: international judicial cooperation in criminal matters; extradition; surrender; European arrest warrant; mutual recognition; mutual trust; fundamental rights.

1. O presente número da Revista Brasileira de Direito Processual Penal, que tenho o privilégio de editar, é inteiramente dedicado à cooperação judiciária internacional em matéria penal (CJI).

Importa consignar, logo no início, uma explicação sobre a terminologia usada, que tenho discutido recorrentemente ao longo da última década com os meus alunos e orientandos brasileiros. Com efeito, embora a literatura brasileira se refira comummente à "cooperação jurídica”, prefiro continuar a empregar, para designar a temática que é objecto deste volume, a fórmula “cooperação judiciária”. A meu ver, a expressão cooperação jurídica remete-nos para o âmbito da cooperação, que assim se contradistingue da cooperação em matéria de defesa, segurança, inteligência, educação, saúde, etc. Diferentemente, a cooperação judiciária aponta para uma dimensão funcional / teleológica que delimita com mais precisão, dentro da cooperação internacional "em matéria jurídica”, certos procedimentos levados a cabo no exercício da função judicial por parte dos órgãos aos quais ela se encontra reservada. A CJI visa sempre um processo penal concreto e convoca, por isso, a actuação de juízes e magistrados do Ministério Público ${ }^{2}$, sem prejuízo da intervenção que a lei eventualmente atribua ao Executivo para salvaguarda dos interesses de natureza política que ali possam estar envolvidos. Por conseguinte,

2 O art. 1. ${ }^{\circ}$, al. b), do Código de Processo Penal Português qualifica de "autoridade judiciária” os juízes, juízes de instrução e os magistrados do Ministério Público; vd. também, com muito interesse, Dias, Jorge de Figueiredo, "Nótulas sobre temas de direito judiciário (penal)", Revista de Legislação e Jurisprudência 127 (1995), n. ${ }^{\circ} 3849$, p. 354 e ss., e 128 (1995), n. ${ }^{\circ} 3850 / 3851$, p. 8 e ss., que justamente inclui a "magistratura do Ministério Público", enquanto estrutura dotada de autonomia (mas não de independência), na "função judicial”, negando-lhe a natureza de "órgão administrativo" (vd. esp. n. ${ }^{\circ} 3849$, p. 355 e s. e p. 357 , n. 14 ). 
ficam excluídos da noção de cooperação judiciária os procedimentos de auxílio mútuo e de partilha de informação estabelecidos entre forças de segurança (cooperação policial) ou serviços de inteligência, mesmo quando tenham alguma atinência com crimes.

Aliás, creio que o Estado Português teve bem presente esta distinção entre âmbito e função quando celebrou vários acordos internacionais que têm por título e/ou conteúdo "cooperação jurídica e judiciária"

2. Não será necessário encarecer a importância crescente que a CJI vem ganhando nas últimas décadas, ao ritmo de um mais geral fenómeno de "encurtamento do mundo".

3 Parece existir um modelo-padrão sobre o qual foram decalcados vários acordos de cooperação entre Portugal e outros países de língua oficial portuguesa (Acordo de Cooperação Jurídica entre a República Portuguesa e a República da Guiné-Bissau, assinado em Bissau em 5-07-1988 e ratificado pelo Presidente da República em 16-06-1989; Acordo de Cooperação Jurídica e Judiciária entre a República Portuguesa e a República de Moçambique, assinado em Lisboa a 1204-1990 e ratificado pelo Presidente da República em 11-12-1990; Acordo de Cooperação Jurídica e Judiciária entre a República Portuguesa e a República de Angola, assinado em Luanda em 30-08-1995 e ratificado pelo Presidente da República em 31-01-1997; Acordo de Cooperação Jurídica e Judiciária entre a República Portuguesa e a República de Cabo Verde, assinado na Praia em 2-122003 e ratificado pelo Presidente da República em 28-01-2005).

Estes acordos são compostos por uma longa Parte I relativa à “cooperação judiciária" (em matéria cível e em matéria penal) e por uma Parte II relativa à "cooperação em matéria de identificação, registos e notariado, formação e informação" (o Acordo com Cabo Verde encontra-se dividido em títulos, sendo os Títulos II e III correspondentes à Parte I e o Título IV à Parte II dos restantes). Essa Parte II contém um Título IV, cuja epígrafe é "Cooperação técnica, jurídica e documental" e que tem um único artigo, onde se descrevem as respectivas "modalidades": " 1 - Os Estados Contratantes, na medida das suas possibilidades, prestar-se-ão colaboração formativa e informativa no âmbito técnico, jurídico e documental nos campos abrangidos pelo presente Acordo. 2 - Sem prejuízo de outras modalidades de colaboração documental a concertar entre os departamentos competentes, os Estados Contratantes trocarão gratuitamente entre si os respectivos jornais oficiais. 3 - As entidades editoras de cada um dos Estados enviarão desde já um exemplar de cada número e série do respectivo jornal oficial à Procuradoria-Geral da República do outro. 4 - A colaboração na formação de pessoal será objecto de acordos específicos" (itálicos nossos; no Acordo com Cabo Verde, vd. o correspondente art. 83. ${ }^{\circ}$, que tem por epígrafe "Informação jurídica"). 
As inovações técnicas em matéria de transportes e a redução dos custos das viagens, por um lado, e a diminuição ou abolição dos entraves administrativos/burocráticos à circulação de pessoas, por outro, estimularam a massificação e normalização dos fluxos trans-fronteiriços.

Este fortalecimento da capacidade individual de transpor a fronteira contrasta com a persistência da natureza essencialmente local/nacional da administração da justiça penal, tanto no plano da jurisdição ${ }^{4}$, como, no que aqui mais importa, no plano processual. Com efeito, a territorialidade do processo penal entra em tensão com os limites da jurisdição executiva impostos pelo princípio da não-ingerência, na medida em que um Estado não pode enviar os seus agentes para colher prova ou deter um suspeito/ acusado/condenado que se encontram no território de outro Estado. Essa tensão só pode resolver-se por meio da cooperação judiciária, seja com a entrega das pessoas ou a remessa dos elementos pretendidos pelo Estado requerente, seja com a aceitação, pelo Estado requerido, da transmissão / delegação do processo penal.

Ora, há três factores que trouxeram maior permeabilidade às pretensões punitivas dos outros Estados e, por aí, à cooperação judiciária: (i) a percepção de que a prevenção e repressão de certas formas de criminalidade grave internacional exigem uma acção conjunta dos Estados; (ii) o melhor conhecimento dos ordenamentos jurídicos estrangeiros possibilitado pelo desenvolvimento das tecnologias de informação e pelas redes internacionais de profissionais forenses e académicos; e (iii) o incremento, em termos globais, do respeito pelos direitos humanos e pelo Estado de direito. Não surpreende, portanto, que a evolução sócio-económica das últimas décadas tenha sido acompanhada por uma intensificação da CJI, que encontra expressão na proliferação de instrumentos internacionais e, sobretudo, no aumento da respectiva efectividade.

4 Refiro-me à actual consagração da territorialidade dos factos como regra-base da aplicabilidade da lei penal em todos os ordenamentos jurídicos e ao condicionamento da jurisdição judicativa à presença do agente no território nacional em alguns deles (vd., p. ex., o art. 7., II, al. b), e $§ 2 .^{\circ}$, al. a), do Código Penal Brasileiro; e o art. 5. ${ }^{\circ}$, n. ${ }^{\circ}$, als. c), d), e) e f) do Código Penal Português). Sobre o conceito de jurisdição penal e as respectivas dimensões, vd. CAeiro, Pedro, Fundamento, Conteúdo e Limites da Jurisdição Penal do Estado. O Caso Português, Wolters Kluwer / Coimbra Editora, 2010. 
Por outro lado, a progressiva ampliação do alcance do poder punitivo de cada Estado por via da extensão da eficácia extraterritorial das leis e da CJI abre novas perspectivas sobre o ponto de equilíbrio que hoje se estabelece entre o poder público e os direitos individuais. Em particular, torna-se premente reflectir sobre esta virtual universalização de pretensões locais/nacionais, que, no campo da CJI, se traduz em criar mecanismos pelos quais cada Estado presta aos restantes o auxílio necessário à prossecução dos respectivos programas de política criminal, que não exige necessariamente a natureza criminosa dos concretos factos em causa (abolição ou flexibilização do controle da dupla incriminação) $)^{5}$. Nestes casos, há que levar a sério os direitos e garantias da pessoa visada, nomeadamente o direito à segurança jurídica e o direito a ser deixado em paz, pois trata-se de alguém que não violou as leis do Estado onde se encontra, nem praticou actos que estas, em abstracto, reprovem. Assim, a cooperação prestada pelo Estado requerido - e, sobretudo, a concessão da extradição - nestas condições suscita problemas de legitimidade, excepto se se enquadrar em projectos integrados de justiça comum, como sucede na União Europeia e poderá vir a ocorrer no espaço do Mercosul.

3. Os projectos de justiça comum que acabei de referir são cruciais para a compreensão da CJI contemporânea. Para além dos "modelos verticais" (A. Cassese) de cooperação corporizados nos estatutos dos tribunais penais internacionais ${ }^{6}$, deve destacar-se a verdadeira revolução trazida pela concepção da União Europeia, no Tratado de Amesterdão, como um espaço de liberdade, segurança e justiça, no âmbito do qual se forjaram os instrumentos que passaram a reger a cooperação judiciária entre os Estados-Membros, e, nomeadamente, a paradigmática e seminal Decisão-quadro sobre o mandado de detenção europeu,

5 No mesmo sentido vai a redução, até ao grau da irrelevância, do âmbito da excepção do crime politico.

6 Vd., de forma exemplar, o regime da cooperação (e, em particular, do procedimento de entrega) constante dos arts. 86 e ss. do Estatuto de Roma do Tribunal Penal Internacional. 
de $2002^{7}$. Assentes sobre a pedra angular do "reconhecimento mútuo das decisões judiciais", que por sua vez se funda na "confiança mútua" que liga os Estados-membros, aqueles instrumentos pretenderam transportar para a cooperação em matéria penal a lógica da "livre circulação das decisões judiciais” que vigora no mercado interno. Assim, e não obstante as diferenças que subsistem entre os mecanismos nos dois domínios - inerentes à diversidade das funções estatais implicadas no reconhecimento de direitos e liberdades e no reconhecimento das decisões que os restringem -, a CJI na União Europeia foi profundamente modificada, sendo hoje mais efectiva, mais célere e mais difícil de recusar.

A judicialização integral do procedimento (com absoluta exclusão da intervenção do Executivo), a abolição do controlo da dupla incriminação em relação a trinta e dois "domínios de criminalidade", a descrição taxativa dos "motivos de não execução" (obrigatórios e facultativos) e a previsão de prazos curtos para a tomada de decisões fazem destes instrumentos poderosas ferramentas nas mãos dos Estados e permitem certamente ver neles um modelo autónomo de cooperação judiciária. Porém, após uma fase inicial em que o reconhecimento mútuo serviu de verdadeira correia de transmissão do Estado titular da pretensão punitiva, garantindo a máxima efectividade aos seus pedidos, é hoje inequívoco que a confiança mútua tem limites e a presunção de respeito pelos direitos fundamentais que lhe subjaz pode ser ilidida no caso concreto $^{8}$, de tal modo que não se deva dar seguimento ao pedido de cooperação ${ }^{9}$. Com este sentido, o princípio do reconhecimento mútuo tende a tornar-se num mecanismo formal, neutro, que visa apenas obrigar os Estados Membros ao reconhecimento das decisões tomadas em conformidade com o direito da União globalmente considerado (aí se incluindo a Carta dos Direitos Fundamentais da União Europeia) -

7 Decisão-quadro do Conselho 2002/584/JAI, de 13 de Junho de 2002, relativa ao mandado de detenção europeu e aos processos de entrega entre os Estados-Membros, JO L 190, de 18-07-2002.

8 Acórdão do Tribunal de Justiça (Grande Secção), procs. apensos C-404/15 e C-659/15 PPU, Pál Aranyosi e Robert Căldăraru, de 5 de Abril de 2016 | ECLI:EU:C:2016:198.

9 Acórdão do Tribunal de Justiça (Grande Secção), C-216/18 PPU, LM, de 25 de Julho de 2018, par. 78 | ECLI:EU:C:2018:586. 
independentemente de elas serem proferidas pelo Estado que pede ou pelo que presta a cooperação.

4. Por fim, gostaria de salientar um último perfil da CJI que tende a ser menorizado, e que é a sua inarredável dimensão política. A intervenção de interesses da ordem da soberania, política externa, oportunidade e conveniência, irredutíveis à justiça e à legalidade, é uma constante da CJI, porque se trata sempre de uma instância das relações com outros Estados. Bastará pensar nas incidências do processo de extradição de Augusto Pinochet no Reino Unido, no conflito entre o Tribunal Penal Internacional e certos Estados que são Partes no Estatuto de Roma em virtude de não terem procedido à detenção e entrega do recentemente deposto Presidente do Sudão Omar al-Bashir, na miríade de considerações políticas que envolve os pedidos de extradição de Edward Snowden e Julian Assange, ou nas sucessivas decisões de sentido oposto que atravessaram o processo de extradição de Cesare Battisti no Brasil.

A assumida relevância dos interesses dessa natureza projectase no papel reservado ao Executivo dos diversos países nos processos tradicionais de CJI, em particular de extradição. Porém, e sintomaticamente, ela não deixa de afectar - ainda que de jeito menos visível e informal - certos casos de cooperação processados em contextos de onde a componente política está supostamente excluída, como sucede com o mandado de detenção europeu na União Europeia. Na verdade, ninguém negará a tensão política que esteve subjacente, em todos os momentos, ao tratamento do caso Puigdemont pelas autoridades espanholas, belgas e alemãs. O que não surpreende, precisamente porque o espaço judiciário de liberdade, segurança e justiça não tem correspondência directa na esfera política, que continua a ser dominada, em grande medida, pelos interesses particulares de cada Estado-membro.

5. Os artigos que compõem este número especial abordam uma vasta panóplia de dimensões da cooperação judiciária internacional em matéria penal, em contextos que se espraiam por três continentes - do puramente interno ao global, passando por relações bilaterais e estruturas 
regionais - e em planos diferenciados - de reflexões genéricas sobre a cooperação a estudos dedicados a sub-temas específicos, como a extradição / entrega, o auxílio judiciário mútuo, a transferência de pessoas condenadas, o reconhecimento de medidas (civis) de protecção de vítimas e a aplicação dos mecanismos da cooperação a certas formas de criminalidade ou a casos concretos.

O volume abre com um artigo de Valsamis Mitsilegas, que aceitou o convite para expor, em perspectiva panorâmica, o contexto e a evolução da CJI na União Europeia, focando-se no progressivo entrelaçamento entre o princípio do reconhecimento mútuo e o respeito pelos direitos fundamentais e na paulatina substituição da ideia de "confiança cega" pela de "confiança merecida".

Segue-se um primeiro grupo de estudos centrados na CJI "tradicional”. Daniel Leonhardt dos Santos expõe o geral desfasamento entre a vetustez das regras que estabelecem o âmbito de eficácia das leis penais nacionais e a actual criminalidade transnacional, mostrando como tal desfasamento, associado à limitação territorial da "jurisdição prerrogativa” dos Estados, intensifica a necessidade de cooperação internacional. O horizonte problemático da relação entre o crime e as novas tecnologias é partilhado por Ana Paula Gonzatti da Silva, que se dedica à determinação dos limites da jurisdição brasileira quando se trata de obter dados electrónicos armazenados em servidores localizados nos Estados Unidos da América e à análise da necessidade de mobilizar (e criar) mecanismos de CJI para o efeito. Aquela relação entre a CJI e a nova criminalidade internacional é retomada por Anna Carolina Canestraro, que salienta as virtualidades do auxílio judiciário mútuo na prevenção e repressão do crime de branqueamento / lavagem, no quadro das recomendações do GAFI e do direito brasileiro, como forma de cooperação que permite uma circulação célere da informação entre as autoridades. Por seu turno, Fábio Ramazzini Bechara, Gianpaolo Poggio Smanio e Karin Bianchini Girardi trazem-nos uma análise da CJI como law in action, baseada em dados empíricos colhidos num caso concreto, e concluem que um padrão harmonizado de direitos humanos e a vinculação recíproca decorrente da participação em instrumentos internacionais de supressão do crime constituem estímulos poderosos à cooperação. A encerrar este conjunto de artigos sobre a CJI, Miguel 
Manero de Lemos e Teresa Lancry Robalo, escrevendo dos antípodas, tratam o problema sui generis da cooperação “intra-estatal” da República Popular da China ("Mainland") com as regiões administrativas especiais de Hong Kong e de Macau, tendo por pano de fundo a complexa tessitura política onde se inscrevem as respectivas relações, e apontam vias de solução para o impasse causado pela actual ausência de regulamentação.

O segundo grupo de artigos é dedicado à CJI na União Europeia (UE). A ligar os dois conjuntos está o texto de Miguel João Costa, que, depois de revisitar criticamente a proibição da extradição de nacionais, se debruça sobre as repercussões das "políticas de amizade" sobre a CJI, examinando e comparando a (não-)extradição de nacionais de outros países no contexto das relações Brasil-Portugal e no âmbito da União Europeia. Seguidamente, Eduardo Bolsoni Riboli analisa o processo de harmonização das leis penais dos Estados-membros da UE como pressuposto relevante para o desenvolvimento da CJI no espaço de liberdade, segurança e justiça. Por seu lado, Celso Costa Lima Verde Leal expõe as relações entre o mandado de detenção europeu e a protecção dos direitos fundamentais, pondo em evidência como a evolução da jurisprudência do Tribunal de Justiça tem desempenhado um papel crucial no processo da respectiva conciliação. Ainda no domínio do mandado de detenção europeu, Jorge Bheron Rocha foca a sua atenção na causa de não execução "nacionalidade / residência" da pessoa procurada tal como tratada pela jurisprudência dos tribunais portugueses, identificando e apreciando as grandes linhas que a orientam, nomeadamente no que diz respeito aos critérios usados nas decisões e às respectivas consequências. Num outro plano, a cooperação na execução de penas de prisão (transferência de pessoas condenadas) e de sanções alternativas é decerto, como mostra Stefano Montaldo, um dos domínios que encerra maiores desafios para o futuro, não só pela difícil angariação de uma definição europeia e vinculante das finalidades da execução das sanções, mas também porque se trata de um terreno permeável a interesses que pouco ou nada têm que ver com a ressocialização. No lado reverso da medalha, o mesmo défice de harmonização dos ordenamentos jurídicos nacionais afecta também, de acordo com Katixa Etxebarria Estankona, a eficácia do sistema 
europeu de cooperação para a protecção das vítimas de crimes (em particular das vítimas de violência de género), já de si fragmentado nas duas bases jurídicas que o sustêm. Por último, o artigo de Margarida Santos faz uma recapitulação da matéria e abre novas vias de reflexão, reenquadrando a CJI na problemática mais geral da intervenção da UE em matéria penal e examinando, a seguir, o sentido e o alcance do lançamento da Procuradoria Europeia na perspectiva da tensão entre integração e cooperação (inter-estatal).

6. Para além da qualidade científica dos textos, o critério que mais marcou esta edição foi a preocupação em trazer ao leitor temas da maior actualidade suscitados pela CJI em vários azimutes, a qual, aliada à riqueza e à diversidade das abordagens, permite esperar o interesse de académicos e profissionais envolvidos na CJI, no Brasil e nas restantes jurisdições relevantes. Oxalá esta expectativa possa cumprir-se.

\section{REFERÊNCIAS}

Caeiro, Pedro, Fundamento, Conteúdo e Limites da Jurisdição Penal do Estado. O Caso Português. Wolters Kluwer / Coimbra Editora, 2010.

Dias, Jorge de Figueiredo Nótulas sobre temas de direito judiciário (penal). Revista de Legislação e Jurisprudência, v. 127, n. ${ }^{\circ} 3849$, p. 354 e ss., 1995, e v. 128, n. ${ }^{\circ}$ 3850/3851, p. 8 e ss., 1995. 


\section{Informações adicionais e declarações do autor (integridade científica)}

Declaração de conflito de interesses (conflict of interest declaration): o autor confirma que não há conflitos de interesse na realização das pesquisas expostas e na redação deste editorial.

Declaração de autoria (declaration of authorship): todas e somente as pessoas que atendem os requisitos de autoria deste editorial estão listadas como autores; todos os coautores se responsabilizam integralmente por este trabalho em sua totalidade.

Declaração de ineditismo e originalidade (declaration of originality): o autor assegura que o texto aqui publicado não foi divulgado anteriormente em outro meio e que futura republicação somente se realizará com a indicação expressa da referência desta publicação original; também atesta que não há plágio de terceiros ou autoplágio

\section{COMO CITAR ESTE EDITORIAL:}

CAEIRO, Pedro. Editorial do dossiê "Cooperação Judiciária Internacional em Matéria Penal" - Problemas actuais em perspectiva global. Revista Brasileira de Direito Processual Penal, Porto Alegre, vol. 5, n. 2, p. 553-563, mai./ago. 2019. https://doi.org/10.22197/rbdpp.v5i2.249

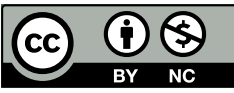

Esta obra está licenciada com uma Licença Creative Commons Atribuição-NãoComercial 4.0 Internacional. 